\title{
An investigation of demand and exchange rate shocks in the tourism sector
}

\author{
Kurtulus Bozkurt and Hatice Armutçuoğlu Tekin \\ Department of Economics, Aydin Adnan Menderes University, \\ Aydin, Turkey, and \\ Zeliha Can Ergün \\ Department of International Trade and Business, \\ Aydin Adnan Menderes University, Aydin, Turkey
}

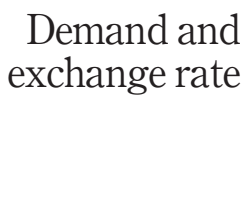

Received 27 May 2020 Revised 4 December 2020 16 January 2021 Accepted 17 February 2021

\begin{abstract}
Purpose - This study aims to measure the relationship between demand and exchange rate shocks in the tourism industry.

Design/methodology/approach - A panel data set is constructed covering the period between 1995 and 2017, and the data set includes the top 26 countries that host 10 million tourists and above in the world as of 2017. The standard errors of the series are used as an indicator of shocks. First, the cross-sectional dependency, stationarity and the homogeneity of the series are examined; second, a panel cointegration analysis is implemented; third, long-term panel cointegration coefficients are analyzed with Dynamic Common Correlated Effects (DCCE) approach; and, finally, Dumitrescu and Hurlin's (2012) Granger noncausality test is used to detect the causality.

Findings - The preliminary analyses show that the variables are cross-sectional dependent and heterogeneous and are stationary in their first difference; hence, the effects of the shocks are temporary. On the other hand, as a result of the panel cointegration analysis, it is found that both series are cointegrated over the long-term. However, the long-term coefficients estimated with the DCCE approach are found not to be statistically significant. Finally, as a result of the Dumitrescu and Hurlin's (2012) Granger non-causality test, it is concluded that there is a causality running from exchange rate shocks to demand shocks.

Originality/value - To the best of the authors' knowledge, the cointegration between the tourism demand shocks and exchange rates shocks has not been investigated before, and therefore, this study is considered to be a pioneering study that will contribute to the literature.
\end{abstract}

Keywords Causality, Cointegration, Panel data analysis, Exchange rate shocks, Tourism demand shocks

Paper type Research paper

(C) Kurtulus Bozkurt, Hatice Armutçuoğlu Tekin and Zeliha Can Ergün. Published in Applied Economic Analysis. Published by Emerald Publishing Limited. This article is published under the Creative Commons Attribution (CC BY 4.0) licence. Anyone may reproduce, distribute, translate and create derivative works of this article (for both commercial and non-commercial purposes), subject to full attribution to the original publication and authors. The full terms of this licence maybe seen at http://creativecommons.org/licences/by/4.0/legalcode

JEL classification - F31, Z30

The authors would like to thank editors and anonymous reviewers for various comments that helped them improve earlier versions of the manuscript.

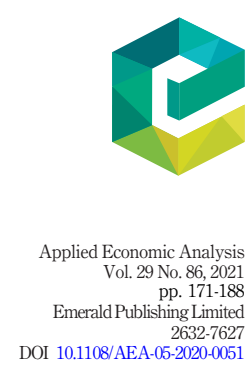


AEA

29,86

\section{Introduction}

The tourism sector is one of the sectors that bring the most revenue to the countries. However, because of security weaknesses such as economic difficulties, exchange rate shocks and terrorist attacks; the demand decreases, and in turn, this causes a decrease in the sources of revenue. The sudden changes in the amount of tourism demand are called tourism demand shocks. In the economy, to provide the sustainability of the goods and services or the sustainability of the supply, the incoming demand shocks should not be permanent. The reason is that in the tourism sector the costs of investments mostly consist of fixed costs, and in the economy when the costs are mostly composed of fixed costs, this creates a barrier to exit from the sector. In these kinds of periods, the competitive pressure is felt significantly in the tourism sector, and the barrier to exit may lead to a decrease in demand and increase in loss on a firm basis, and also it may lead to a decrease in revenues in the country's overall economy. One of the most important reasons for this is the fact that the tourism sector creates a multiplier effect on the economy.

While the tourism sector provides income to many industries such as furniture, construction, textile and food sectors, it is thought that the recession in this sector has an impact on the remaining sectors, too. Concordantly, it is important to determine whether the demand shocks occurring in this sector are permanent or temporary. Bozkurt and Bahar (2015, p. 30) stated that when the shocks are permanent, the payback period of investments extends, the expected revenues decrease and the sustainability of the profits becomes risky, in contrast when the shocks are temporary, these negative effects will not be experienced.

According to this information, in this study, first, whether the exchange rate shocks have an effect on tourism demand shocks, and second whether tourism demand shocks have an effect on exchange rate shocks are investigated. Considering the first impact, it could be argued that the tourism sector is one of the country's most important foreign exchange sources. For that reason, the main hypothesis of the study is that if the shock occurs in exchange rates, it will also have an impact on tourism demand. However, this foresight could be materialized as expected only if the revenues from the tourism sector depend mostly on foreign demand. When considered from this point of view, it will be possible to interpret the demand structures of the analyzed countries.

Considering the second effect, when a sudden decline occurs in foreign demand, foreign exchange inflow to the country will decrease based on the tourism sector. In turn, in this condition, because the foreign currency will be more scarce in the market, it will gain value; and eventually, the domestic currency will lose value. Therefore, also, it can be expected that demand shocks that occur in the tourism sector will cause exchange rate shocks. However, the impact of the other economic components of the country, such as export and import structures, should not be ignored while evaluating the share of the tourism sector in the country's economy.

Besides, whether the firms in the tourism sector compete with goods differentiation (destination differentiation) or price differentiation is the most important determinant of the relationship between these two variables. The reason is that, along with the exchange rates, the destination and the domestic price differences are also a determinant of the tourism demand (Webber, 2001, p. 404). If the destination has idiosyncratic service differentiation and features, it can be said that in this region the price elasticity in the tourism sector is low, so the demand is less affected by the price changes. On the other hand, if the tourism sector in the country attracts tourists with its low prices, and if the price elasticity is higher, the demand is more affected by the price changes. In sum, price elasticity must be strong in the event of exchange rate shocks triggering tourism demand shocks. 
Moreover, the volatility in exchange rates or the price differences may cause tourists to desist from the idea of a holiday or to change their vacation preferences. As stated by Patsouratis et al. (2005), in general, variables such as the country's revenue, the general level of prices, substitution prices, population and exchange rates are used as the determinants of the tourism demand. Although there are many determinants of tourism demand, this study focuses on the relationship between demand shocks and exchange rate shocks in the tourism sector.

Concordantly, among previous literature, the study of Dritsakis (2004, p. 113) is the Demand and exchange rate closest to the scope of this study, and there, it was stated that in the economic framework there may be a negative relationship between the tourism demand and the real exchange rates, and in the long run, these variables act together, that is, there is a cointegration relationship between these two variables. However, the study of Dritsakis (2004) has not considered the shocks that arise from these two variables. To the best of the authors' knowledge, in the previous literature, none of the studies examined whether the tourism demand shocks and exchange rate shocks act together. In other words, the cointegration between these two variables has not been investigated before, and therefore, this study is considered to be a pioneering study that will contribute to the literature.

The rest of the study is structured as follows: Section 2 summarizes the previous literature. Section 3 clarifies the methodology. Section 4 explains the data and empirical results. Finally, Section 5 concludes with the discussion of the findings.

\section{Literature review}

In the literature review part of the study, first, the studies investigating the effects of economic uncertainty on tourism demand shocks; second, the studies analyzing whether the shocks in the tourism sector are permanent or temporary; third, the studies examining the relationship between exchange rate volatility and tourism demand; and finally, the studies trying to find out the effects of exchange rate on tourism demand are scrutinized.

Table 1 presents a summary of the examined literature in terms of the method and the results. In their study, Bhattacharya and Narayan (2005), Narayan (2005), Lean and Smyth (2009), Lee (2009), and Smyth et al. (2009) investigated whether the shocks in tourism demand are temporary or permanent, and they generally concluded that shocks occurring in the tourism sector are temporary.

Bhattacharya and Narayan (2005) measured the permanence of tourism demand shocks in India for the years 1980-1999, and they examined whether the unit root of the number of inbound tourists from the top 10 economies is stationary. According to this study, it is stated that if there is a unit root in the number of inbound tourists, the shocks are permanent and if there is no unit root, the shocks are temporary. Bhattacharya and Narayan (2005) analyzed the shocks in tourism demand with Maddala and $\mathrm{Wu}(1999)$ panel unit root test. As a result of their study, they found that in India the shocks in tourism demand have a short-term impact and these shocks are not permanent in the long-term.

Narayan (2005) investigated whether the shocks occurring in the tourism industry in Fiji have a permanent or temporary effect on tourism expenditures. In the analyses, Zivot and Andrews (2002) and Lumsdaine and Papell (1997) unit root tests were used which consider the structural breaks in the data set. As a result, it is found that the shocks occurring in the tourism industry of Fiji do not have a permanent effect; the effects of the shocks are temporary.

Lean and Smyth (2009) examined when a structural break occurs because of the effect of events such as avian influenza, terrorist attacks, and Asian financial crisis, whether the shocks in the number of inbound tourists from the top 10 tourist generating countries to 


Author(s) Methodology Results

Toh et al. (1997)

Webber (2001)

174

Dritsakis (2004)

Bhattacharya and

Narayan (2005)

Narayan (2005)

Shareeff and McAleer

(2005)

Lean and Smyth (2009)

Lee (2009)

Smyth et al. (2009)

Santana-Gallego et al.

(2010)

Table 1.

Balli et al. (2018)
Regression Analysis

Johansen and Engle Granger Cointegration Method

Johansen Maximum Likelihood Procedure, VAR Model, ECM

Maddala and Wu Panel Unit Root Test

Zivot and Andrews (2002) One

Break Test and Lumsdaine and Papell (1997) Two Break Test GARCH-GJR

Lagrange Multiplier (LM) Unit Root Tests with One and Two Structural Breaks

Augmented Dickey and Fuller and Kwiatkowski et al. Tests

Univariate and Panel LM Unit Root Tests with One and Two Structural Breaks

Panel Data Analysis, Pooled OLS, FE-2SLS, RE-2SLS

Multiple and Partial Wavelet Analyzes
Exchange rates have a very limited effect on the expected number of tourists

There is a long-term relationship between exchange rate volatility and tourism demand

There is a cointegration relationship between exchange rates and tourism demand

The shocks in the tourism demand of the Indian economy are temporary Shocks occurring in the tourism industry in Fiji have a temporary effect on tourism expenditures

Uncertainty in the economy causes shocks in tourism demand

The impact of shocks is temporary in the presence of structural breaks in the Malaysian economy

The impact of external shocks in Singapore's tourism demand is temporary on tourists from nine countries, while tourists from three countries are not affected by these shocks Terrorist attacks in Bali cause temporary shocks in the number of tourists coming

Less elastic exchange rates increase tourism demand

While the effects of global economic uncertainties on tourism demand vary by country, local uncertainties significantly affect tourism demand in all countries

Malaysia are permanent, and they analyzed it with the Lagrange multiplier (LM) unit root test which considers one and two structural breaks. As a result of their study, they stated that the structural breaks are temporary, but the decrease in the number of inbound tourists is remarkable, and for that reason, precautions should be taken to reduce the effects of structural breaks.

In another study which is conducted by Lee (2009), the top 12 tourist generating countries to Singapore were considered and the effects of negative shocks such as epidemics and terrorist attacks on the number of tourists coming from these countries are analyzed through the Augmented Dickey and Fuller and Kwiatkowski et al. tests. As a consequence, it was detected that the effect of these negative shocks in the number of tourists coming from 9 out of 12 countries is temporary, whereas three of these countries are not affected by the shocks.

Moreover, Smyth et al. (2009) found out that the impact of shocks caused by bomb terrorism attacks in Bali has a temporary effect on the number of inbound tourists, and they concluded that tourism revenues in Bali are sustainable. As a method, they applied the univariate and panel LM unit root tests with one and two structural breaks method. 
According to Shareeff and McAleer (2005) and Santana-Gallego et al. (2010), the exchange rates and price shocks, and thus the uncertainties in the economy also affect the tourism demand. Shareeff and McAleer (2005) investigated the relationship between the volatility in the tourism economics and the demand of international tourism of the small island countries (Barbados, Cyprus, Dominica, Fiji, Maldives, Seychelles). As a result of the Generalized Autoregressive Conditional Heteroscedasticity (GARCH) and asymmetric GJRGARCH analyzes, they found that uncertainties in the country's economies will cause shocks in tourism demand and hence shocks in the number of inbound tourists (Shareeff and McAleer, 2005, p. 331). As the shocks in exchange rates will cause uncertainty in the economy, the studies of Shareeff and McAleer (2005) and Balli et al. (2018) are also researched in the scope of the literature. Balli et al. (2018) investigated the effects of global and local economic uncertainties on tourism demand with multiple and partial wavelet analysis for various countries. According to their results, while the effects of global economic uncertainties on tourism demand vary by country, local uncertainties significantly affect tourism demand in all countries.

On the other hand, Santana-Gallego et al. (2010) examined the effect of exchange rate systems on international tourism, and they found that when the elasticity of the exchange rates decreases, the tourism demand increases. Besides, when they reviewed the literature, they observed that the exchange rate is an important determinative for the tourism demand and the exchange rate regimes with low uncertainty may encourage tourism (SantanaGallego et al., 2010, p. 30). In the methodology part of their research, they adapted the gravity model which is applied to measure competition in international trade, and with this model, they measured the relationship between the tourism demand and the exchange rate. They empirically estimated this model by using pooled OLS, FE-2SLS and RE-2SLS methods, which are the panel data analyzes.

Moreover, in their study, while Webber (2001) and Dritsakis (2004) concluded that there is a long-term relationship between exchange rate and tourism demand, Toh et al. (1997) stated that exchange rates have a limited effect on tourism demand. Webber (2001) examined the relationship between the tourism demand and the exchange rate volatility through the Johansen and Engle-Granger cointegration methods, and it is found that changes in the exchange rate, in the long run, affect the level of tourism demand. This situation indicates that the tourism demand in Australia is significantly affected by the price elasticities of tourism. On the other hand, Dritsakis (2004) investigated the cointegration relationship between the changes in long-term tourism demand and the macroeconomic variables of the top two tourist generating countries to Greece. One of these macroeconomic variables is the exchange rate, and it is concluded that there is a long-term cointegration relationship between the exchange rate and the tourism demand.

Other studies investigating the relationship between the tourism demand and the prices or exchange rates are implemented by Toh et al. (1997), Eliat and Einav (2004) and Patsouratis et al. (2005). Toh et al. (1997) examined the relationship between Singapore's expected number of tourists and the exchange rates for the year 2000, as a result of their regression analyzes, they stated that the exchange rates have a limited effect on the expected number of tourists.

Eliat and Einav (2004) examined the determinants of international tourism with threedimensional panel data analysis, and as a result, they detected that the tourism demand of the developed countries is affected by the price elasticities, but the tourism demand of the developing or less developed countries is not affected from price fluctuations. Finally, Patsouratis et al. (2005), on the other hand, investigated the tourism competition among the 
AEA

29,86

\section{6}

Mediterranean countries, and they concluded that the price index and the exchange rate are the main determinants of the tourism demand.

In sum, the studies on tourism demand mainly focus on the existence of a long-term relationship between the exchange rates and tourism demand. However, none of the studies analyzed the relationship between the shocks in tourism demand and the shocks in exchange rates, and for that reason, the present study aims to fill this gap.

\section{Methodology}

In this research, the short-term and long-term relationships between demand shocks and exchange rate shocks in the tourism sector and the causal relationship between these two variables have been examined within the framework of the related literature. In the analysis of panel data, the approach used affects the efficiency and reliability of the estimate results in the case of cross-sectional dependency and heterogeneity in slope coefficients. For this reason, first, the cross-sectional dependency is analyzed with the Breusch Pagan LM (1980) test. After cross-sectional dependency is determined, the cross-sectional augmented DickeyFuller (CADF) test of Pesaran (2006) is used to determine the panel unit root under crosssectional dependency. In the third step, if the slope coefficients are homogeneous by the unit is evaluated using the homogeneity test suggested by Pesaran and Yamagata (2008), which is the standardized version of Swamy's test.

The cointegration relationship between variables is then investigated with the DurbinHausman (DH) cointegration test developed by Westerlund (2008), which both take into account the cross-sectional dependency and allows for heterogeneous slope coefficients. The Dynamic Common Correlated Effects (DCCE) method developed by Chudik and Pesaran (2015) is used to examine long-term coefficients, taking into account both cross-sectional dependency and heterogeneity coefficient of the slope. Finally, the Dumitrescu and Hurlin (2012) panel causality test is used, which makes it possible to analyze the causal relationship between heterogeneous and cross-sectional dependent variables.

In Section 3, first, the description of the demand and exchange rate shocks will be given, and then the previously mentioned methods used in this study will be clarified.

\subsection{Definition of the shocks}

Before explaining the methods used in this study, the demand and exchange rate shocks will be defined in subsection 3.1. As it is known, the main approach of business cycle theory is to try to explain the reasons for income fluctuations, that is to try to determine the reasons for the change in $\Delta Y$ :

$$
\Delta Y_{t}=Y_{t}-Y_{t-1}
$$

However, the change in income $(\Delta Y)$ includes an autoregressive process inherently. This autoregressive process could be indicated with the following equation (2):

$$
\Delta Y_{t}=p \Delta Y_{t-1}+u_{t}
$$

In equation (2); $u_{t}$ refers to the error term, which reflects the effects of shocks in connection with the autoregressive process, $p$ is the constant under the condition of $p \epsilon[0,1)$. In this process, with a positive shock $\left(u_{t}>0\right)$ the output level will increase, whereas with a negative shock $\left(u_{t}<0\right)$ the output level will decrease.

Generally, the concept of shock mentioned here includes a definition of macroeconomic shock, and therefore, it could be stated that a specific shock definition could also include an 
autoregressive process. Accordingly, in this study, the tourism demand shock with a normal distribution, which includes an autoregressive process, and whose average is different from zero, is used as expressed in equation (3):

$$
\operatorname{lnitr}_{t}=\operatorname{lnitr}_{t-1}+\varepsilon_{i t r, t}
$$

In equation (3); hitr $_{t}$ indicates the natural logarithm of the tourism demand at time $t$, and in conjunction with the autoregressive process; mitr $_{t-1}$ is the natural logarithm of the tourism demand at time $t-1$, and $\varepsilon_{i t r, t}$ refers to the error term which reflects the effects of demand shocks.

Similarly, the exchange rate shock with a normal distribution, which includes an autoregressive process, and whose average is different from zero could be expressed as in equation (4):

$$
\operatorname{lnexc} c_{t}=\operatorname{lnexc}_{t-1}+\varepsilon_{\text {exc }, t}
$$

In equation (4); $\operatorname{lnexc}_{t}$ indicates the exchange rate, and in conjunction with the autoregressive process; $\operatorname{lnexc}_{t-1}$ is the natural logarithm of the exchange rate and $\varepsilon_{\text {exc.t }}$ refers to the error term which reflects the effects of exchange rate shocks.

\subsection{Cross-sectional dependency test}

To investigate the relationship between the demand and exchange rate shocks in the tourism sector, in this study, first, it was examined whether the series contain crosssectional dependency or not. At this point, Breusch Pagan LM (1980) test was used. For the Breusch Pagan LM (1980) test, the following hypotheses are tested:

$$
\mathrm{H}_{0}: \rho_{i j}=\operatorname{cor}\left(u_{i t}, u_{j t}\right)=0(i \neq j) \text { and } \mathrm{H}_{1}: \rho_{i j}=\operatorname{cor}\left(u_{i t}, u_{j t}\right) \neq 0(i \neq j)
$$

In these hypotheses, $\rho_{\text {ij }}$ represents the correlation coefficient between the residuals of the $i$ th and $j$ th cross-sectional unit. At this point, the null hypothesis indicates the absence of correlation between the units, while the alternative hypothesis expresses the cross-sectional dependency. Breusch and Pagan (1980) LM test statistics are calculated as follows:

$$
L M=T \sum_{i=1}^{N-1} \sum_{j=i+1}^{N} \hat{\rho}_{i, j}^{2}
$$

\subsection{Panel unit root test}

After estimating cross-sectional dependency, the CADF test of Pesaran (2006), who tested the panel unit root under cross-sectional dependency, is used. As a result of the simulations of the CADF test, it has been seen that it has reached valid and significant statistical results for both $N \rightarrow \infty$ and $T>N$ and $N>T$ situations.

In the CADF test, based on the following basic ADF equation, an error term definition is made consisting of two different parts: one is common to all series and the other is defined separately for each series. In other words, the spatial correlation was also taken into account under the cross-sectional dependency:

$$
\Delta Y_{i, t}=\alpha_{i}+\beta_{i} Y_{i, t-1}+\delta_{i, t}+\sum_{j=1}^{p_{j}} \varnothing_{i, j} \Delta Y_{i, t-j}+u_{i, t}
$$

where $u_{i, t}=\lambda_{i} f_{t}+\varepsilon_{i, t} ; t=1,2, \ldots, T$; and $i=1,2, \ldots, N$ 
AEA

29,86

In equation (7), the expression $\lambda_{\mathrm{i}}$ shows the independent time effect for each cross-section, and it indicates that in the presence of external processes such as shock or crisis, the effects of external processes will be different for each cross-section. The expression $f_{t}$ in equation (7) shows the unobserved common time effect for all cross-sections, and it is assumed to be stationary. The term $\varepsilon_{i, t}$ in equation (7) represents the error term and it is an independently distributed value that differs for each cross-section.

The null and the alternative hypotheses of the CADF test are as follows. Similar to the SURADF unit root test, the $t$-values for the $\beta$ coefficients are calculated separately for all cross-sections, and they are compared with the critical values:

$$
H_{0}: \beta_{i}=0 \text { for all } \mathrm{i} ; H_{1}: \beta_{i}<0 \text { and } i=1,2, \ldots, N
$$

The ADF equation used by the CADF test is as follows. When $N \rightarrow \infty$, the equation is estimated with the least squares (OLS) method and it is decided whether the cross-sections are stationary or not:

$$
\begin{gathered}
\Delta Y_{i, t}=\alpha_{i}+\beta_{i} Y_{i, t-1}+\sum_{j=1}^{p_{j}} c_{i, j} \Delta Y_{i, t-j}+d_{i} t+h_{i} \bar{y}_{t-1}+\sum_{j=0}^{p_{i}} \eta_{i, j} \Delta \bar{y}_{i, t-j}+\varepsilon_{i, t} \\
t_{i}=\frac{\hat{\beta}_{i}}{\operatorname{Sht}\left(\beta_{i}\right)}=C A D F_{i}
\end{gathered}
$$

\subsection{Slope homogeneity test}

In the next step, to analyze the homogeneity of the slope coefficients in the cointegration equation by unit, the homogeneity test proposed by Pesaran and Yamagata (2008) is used, which is the standardized version of Swamy's test. Pesaran and Yamagata (2008) analyzed the homogeneity of the slope parameters with two different test versions recommended for large samples $(\hat{\Delta})$ and small samples $\left(\widetilde{\Delta}_{a d j}\right)$. Test hypotheses can be expressed as follows through the basic cointegration model seen in equation (11):

$H O: \beta_{i}=\beta$ for all $\mathrm{i}$, and H1: $\beta_{i} \neq \beta_{j}$

$$
Y_{i t}=\alpha+\beta_{i} X_{i t}+\varepsilon_{i t}
$$

The test statistics for the first version $(\hat{\Delta})$ and the second version $\left(\widetilde{\Delta}_{\text {adj }}\right)$ are calculated as follows:

$$
\tilde{\Delta}=\sqrt{N}\left(\frac{N^{-1} \hat{S}-k}{\sqrt{2 k}}\right) \text { and } \tilde{\Delta}_{a d j}=\sqrt{N}\left(\frac{N^{-1} \hat{S}-E\left(\tilde{Z}_{i T}\right)}{\sqrt{\operatorname{Var}\left(\tilde{Z}_{i T}\right)}}\right)
$$

\subsection{Cointegration analysis and estimation of the coefficients}

After these preliminary analyzes, first, the cointegration analysis is performed to test whether there is a long-term relationship between the series and then the panel cointegration coefficients are estimated. Accordingly, in this study, DH cointegration test developed by Westerlund (2008) will be used, and this test takes into account the cross-sectional 
dependency and allows the slope coefficients to be heterogeneous. The DH cointegration test has two dimensions as the panel size and the group size. The assumption of the DH panel $\left(\mathrm{DH}_{\mathrm{p}}\right)$ test is that the autoregressive parameter is common for each cross-section. With this assumption, if the null hypothesis is rejected, it means there is cointegration for all crosssections. The $\mathrm{DH}$ group $\left(\mathrm{DH}_{\mathrm{g}}\right)$ test allows the autoregressive parameter to vary between cross-sections under the alternative hypothesis. Therefore, rejecting the null hypothesis suggests that cointegration exists for some cross-sections (Westerlund, 2008). $\mathrm{DH}_{\mathrm{p}}$ and $\mathrm{DH}_{\mathrm{g}}$ test statistics and hypotheses are as follows:

$$
\begin{aligned}
& D H_{p}=\hat{S}_{n}(\tilde{\varnothing}-\hat{\varnothing})^{2} \sum_{i=1}^{n} \sum_{t=2}^{T} \hat{e}_{i t-1}^{2} \\
& H_{0}: \varnothing_{i}=1(\text { for all } i) \text { and } H_{1}: \varnothing_{i}=\varnothing \text { ve } \varnothing<1(\text { for all } i) \\
& D H_{g}=\sum_{i=1}^{n} \hat{S}_{i}\left(\tilde{\varnothing}_{i}-\hat{\varnothing}_{i}\right)^{2} \sum_{t=2}^{T} \hat{e}_{i t-1}^{2} \\
& \left.H_{0}: \varnothing_{i}=1(\text { for all } i) \text { and } H_{1}: \varnothing_{i}<1 \text { (at least some } i\right)
\end{aligned}
$$

For the next step, the DCCE method developed by Chudik and Pesaran (2015) is used to estimate the coefficients of panel cointegration, as this new method has extended the common correlated effects methodology, which is discussed in the original paper of Pesaran (2006). This extended method could be applied in heterogeneous panel data models in which weak exogenous variables and lagged values of dependent variables are included. In the DCCE estimator, unit-specific cross-sectional means of variables are included in the model to represent the unobserved factors. The general view of the linear covariance stationary dynamic heterogeneous panel data model proposed by Chudik and Pesaran (2015) is as follows:

$$
\begin{gathered}
y_{i t}=c_{y i}+\varnothing_{i} y_{i, t-1}+\beta_{0 i}^{\prime} x_{i t}+\beta_{1 i}^{\prime} x_{i, t-1}+u_{i t} \\
u_{i t}=\gamma_{i}^{\prime} f_{t}+\varepsilon_{i t}
\end{gathered}
$$

In equations (15) and (16), $y_{i t}$ is the dependent variable, where $\mathrm{i}=1,2, \ldots, \mathrm{N}$ and $\mathrm{t}=1,2, \ldots$, T. On the other hand, $x_{i t}$ and $x_{i, \mathrm{t}-1}$ are the independent variables. There, $c_{y i}$ is the constant effect for each cross-section; $x_{i t}$ is the $k_{x} \times 1$ vector of the independent variables specific to cross-section units (i) in period t; $f_{t}$ is the $m \times 1$ vector of unobserved common factors; $\varepsilon_{\text {it }}$ is the unit-specific error term. Chudik and Pesaran (2015) defined the lag number of the crosssectional averages included in the model as $\mathrm{p}_{\mathrm{T}}$.

\subsection{Causality analysis}

For the last step, the panel Granger causality test developed by Dumitrescu and Hurlin (2012) is used to estimate the causal relationship between the demand and exchange rate shocks. In this panel causality test, the null hypothesis indicating the absence of the homogeneous Granger causality relationship is tested against the alternative hypothesis that this relationship exists in at least one cross-section. When $X$ and $Y$ denote two stationary processes observed during the $t$ period for $\mathrm{N}$ number of units, the following linear heterogeneous model is considered for each unit $i$ at time $t$ : 


$$
y_{i t}=\alpha_{i}+\sum_{k=1}^{K} \gamma_{i}^{(k)} y_{i, t-k}+\sum_{k=1}^{K} \beta_{i}^{(k)} x_{i, t-k}+\varepsilon_{i, t}
$$

With $K \in N^{*}$ and $\beta_{i}=\left(\beta_{i}^{(1)}, \beta_{i}^{(2)}, \ldots \ldots, \beta_{i}^{(K)}\right)$

In equation (17), it is assumed that individual effects $\left(\alpha_{\mathrm{i}}\right)$ are constant in the dimension, lag parameters $\left(\gamma_{i}^{k}\right)$ and regression slope coefficients $\left(\beta_{i}^{k}\right)$ vary between units. Therefore, a fixed-effects model is established for the causality test. There, the lag orders $\mathrm{K}$ is assumed to be identical for all cross-section units.

Under the null hypothesis, there is no Granger causality between the variables of all units; under the alternative hypothesis, it is stated that there is a causality relationship between two variables in at least one unit. Although the model is heterogeneous, the null hypothesis provides a homogeneous result and the alternative hypothesis provides a heterogeneous result.

The average of the individual Wald test statistics is used to test the null hypothesis of homogenous non-causality (HNC) for units $\mathrm{i}=1, \ldots, \mathrm{N}$ :

$$
W_{N, T}^{H n c}=\frac{1}{N} \sum_{i=1}^{N} W_{i, T}
$$

$\mathrm{W}_{i, T}$ in equation (18) shows the Wald test statistics for ith cross-section unit used to test Granger causality for each country $i$.

As individual Wald statistics for small values of $\mathrm{T}$ do not converge to the same chisquare distribution, Dumitrescu and Hurlin (2012) suggested using the estimated standardized test statistics for $W_{N, T}^{H n c}$ using the estimated values of the mean and variance of this unknown distribution:

$$
\tilde{Z}_{N, T}^{H n c}=\frac{\sqrt{N}\left[W_{N, T}^{H n c}-\sum_{i=1}^{N} E\left(\tilde{W}_{i, T}\right)\right]}{\sqrt{\sum_{i=1}^{N} \operatorname{Var}\left(\tilde{W}_{i, T}\right)}}
$$

Dumitrescu and Hurlin (2012) with the simulations showed that the $\widetilde{Z}_{N, T}^{H n c}$ test statistics have good size and power characteristics even in panels with a small number of units, and this test statistic is quite strong even in the case of incorrect lag length.

This panel Granger causality test, which was brought to the literature by Dumitrescu and Hurlin (2012), can also be applied for unbalanced panels and panels with heterogeneous lag lengths. In this case, instead of equation (19), the test statistic shown in equation (20) should be used:

$$
\begin{aligned}
\tilde{Z}_{N, T}^{H n c} & =\frac{\sqrt{N}\left[W_{N, T}^{H n c}-N^{-1} \sum_{i=1}^{N} E\left(\tilde{W}_{i, T}\right)\right]}{\sqrt{N^{-1} \sum_{i=1}^{N} \operatorname{Var}\left(\tilde{W}_{i, T}\right)}} \\
& =\frac{\sqrt{N}\left[\mathrm{~W}_{N, T}^{H n c}-N^{-1} \sum_{i=1}^{N} K_{-} \times \frac{\left(T_{i}-2 K_{i}-1\right)}{\left(T_{i}-2 K_{i}-3\right)}\right]}{\sqrt{N^{-1} \sum_{i=1}^{N} 2 K_{i} \times \frac{\left(T_{i}-2 K_{i}-1\right)^{2} \times\left(T_{i}-K_{i}-3\right)}{\left(T_{i}-2 K_{i}-3\right)^{2}} \times\left(T_{i}-2 K_{i}-5\right)}}
\end{aligned}
$$


As this study focuses on the empirical analysis of the relationship between demand shocks and exchange rate shocks in the tourism sector, the econometric methodologies used in the study have been briefly defined. It is useful to turn to the appropriate references for more detailed material on the mathematical proof of the methods involved. The data used in the study will now be explained and the results of the analysis will be documented in Section 4 .

\section{Data and empirical results}

To measure the tourism demand shock, the number of inbound tourist data is obtained from the World Development Indicator Database which is published on the World Bank's official website. On the other hand, to measure the exchange rate shock, the real effective exchange rate is used which is obtained from the database of the Central Bank of the Republic of Turkey. The analysis covers the period between 1995-2017. The explanations regarding these variables are given in Table 2.

The countries that constitute the sample group are determined by considering the countries that host 10 million tourists or more as of 2017. These countries are as follows:

\begin{tabular}{|c|c|c|}
\hline Variables & Symbol & Explanation \\
\hline $\begin{array}{l}\text { International tourism, } \\
\text { standard error of the } \\
\text { number of arrivals }\end{array}$ & r_itr $\left(\varepsilon_{i t r, t}\right)$ & $\begin{array}{l}\text { "International inbound tourists (overnight visitors) data is } \\
\text { explained as follows by the World Bank (2019) in the World } \\
\text { Development Indicator database: "International inbound } \\
\text { tourists (overnight visitors) are the number of tourists who } \\
\text { travel to a country other than that in which they have their } \\
\text { usual residence, but outside their usual environment, for a } \\
\text { period not exceeding } 12 \text { months and whose main purpose in } \\
\text { visiting is other than an activity remunerated from within the } \\
\text { country visited. When data on the number of tourists are not } \\
\text { available, the number of visitors, which includes tourists, } \\
\text { same-day visitors, cruise passengers, and crew members, is } \\
\text { shown instead. Sources and collection methods for arrivals } \\
\text { differ across countries. In some cases, data are from border } \\
\text { statistics (police, immigration, and the like) and supplemented } \\
\text { by border surveys. In other cases, data are from tourism } \\
\text { accommodation establishments. For some countries, the } \\
\text { number of arrivals is limited to arrivals by air and for others } \\
\text { to arrivals staying in hotels. Some countries include arrivals } \\
\text { of nationals residing abroad while others do not. Caution } \\
\text { should thus be used in comparing arrivals across countries. } \\
\text { The data on inbound tourists refer to the number of arrivals, } \\
\text { not to the number of people traveling. Thus, a person who } \\
\text { makes several trips to a country during a given period is } \\
\text { counted each time as a new arrival" (The World Bank } \\
\text { DataBank, 2020) }\end{array}$ \\
\hline $\begin{array}{l}\text { Standard error of the } \\
\text { real effective exchange } \\
\text { rate index }(2010=100)\end{array}$ & $\mathrm{r}_{-} \operatorname{exc}\left(\boldsymbol{\varepsilon}_{\mathrm{exc}, \mathrm{t}}\right)$ & $\begin{array}{l}\text { "Real effective exchange rate is the nominal effective } \\
\text { exchange rate (a measure of the value of a currency against a } \\
\text { weighted average of several foreign currencies) divided by a } \\
\text { price deflator or index of costs" (Central Bank of Republic of } \\
\text { Turkey, 2020) } \\
\text { The real effective exchange rate for Turkey is calculated by } \\
\text { considering the price deflator, but the year } 2003 \text { is taken as } \\
\text { the base year. In this study, the base year of the mentioned } \\
\text { data set was rearranged as } 2010\end{array}$ \\
\hline
\end{tabular}


AEA

29,86

\section{2}

Table 3.

Descriptive statistics

Czech Republic, South Africa, Ireland, Morocco, Bahrain, Korea Republic, Singapore, Ukraine, Portugal, Netherlands, Poland, Canada, Russian Federation, Malaysia, Greece, Japan, Austria, Germany, Turkey, UK, Mexico, Italy, China, USA, Spain, France.

Herein, first, the regression models in equations (3) and (4) are estimated, and the series used as the indicator of demand shocks $\left(\varepsilon_{\text {itr,t }}\right)$, and the series used as the indicator of exchange rate shocks $\left(\varepsilon_{\text {exc, }}\right)$ are obtained. The graphics concerning these series are given in Appendix Part Figures A1 and A2. The descriptive statistics regarding these series are given in Table 3 .

In this study, the long-term cointegration relationships between demand shocks and exchange rate shocks in the tourism sector and the causal relationship between these two variables have been investigated within the framework of the related literature. At this point, first, the stationarity and cross-section dependency of the series are evaluated.

As the results of the unit root tests could be influenced by the cross-sectional dependence, the Breusch Pagan LM (1980) test was used for both series, and the results are shown in Table 4 . Because of the test results, As the significance level is less than $1 \%$, it could be reported that both series have cross-sectional dependence.

As cross-sectional dependency is detected in both series, the stationarity of the series is tested by the CADF Panel Unit Root Test of Pesaran (2004), which is one of the second generation unit root tests. In consequence of the analysis, as shown in Table 5 , it is found that both series have a unit root in their level and become stationary when first-differenced.

After the CADF Panel Unit Root Test, the slope heterogeneity test developed by Pesaran and Yamagata (2008) is implemented to detect whether the established model of each country contains slope heterogeneity. Herein, the null hypothesis of slope homogeneity is tested, and the results are presented in Table 6. According to the results, the null hypothesis of slope homogeneity is rejected, and thus the slope of the model is heterogeneous.

In sum, it has been determined from these preliminary analyzes that the variables in the panel data set are cross-sectionally dependent and heterogeneous and are stationary when

\begin{tabular}{lccccc}
\hline Variable & Obs. & Mean & SD & Min. & Max. \\
\hline r_itr & 598 & -0.109944 & 0.522474 & -0.9988012 & 0.9802252 \\
r_exc & 598 & $1.53 \mathrm{e}-09$ & 0.149562 & -0.7187285 & 0.5111256 \\
\hline
\end{tabular}

\section{Table 4.}

Breusch pagan LM (1980) test results

\begin{tabular}{lrr}
\hline Variables & Test & Prob. \\
\hline r_itr & $5,610.18$ & 0.0000 \\
r_exc & 975.47 & 0.0000 \\
\hline
\end{tabular}

\begin{tabular}{lcrr}
\hline Lag length & Variables & Z[t-bar] & Prob. \\
\hline Level & r_itr & 1.601 & 0.945 \\
First-differenced & dr_itr & -18.441 & 0.000 \\
Level & r_exc & -0.605 & 0.273 \\
First-differenced & dr_exc & -19.289 & 0.000 \\
\hline
\end{tabular}


first-differenced. The Westerlund-Durbin-Hausman (2008) cointegration test, as described above, provides reliable and successful results in a cross-section dependent panel data set analysis. Therefore, the Westerlund-Durbin-Hausman (2008) cointegration test is conducted to determine whether there is any cointegration relationship between the tourism demand and the exchange rate shocks over the series. As shown in Table 7, a cointegration relationship between tourism demand and the exchange rate shocks is detected. Group statistics are interpreted for heterogeneous variables, while panel statistics are interpreted for homogeneous panels. For this reason, because the variables in this analysis are heterogeneous, the null hypothesis of no cointegration between the variables is tested and rejected according to the group statistics.

Thereafter, long-term panel cointegration coefficients are analyzed with DCCE approach which is developed by Chudik and Pesaran (2015). In Table 8, DCCE (1) shows the situation where tourism demand shocks are the dependent variable, and DCCE (2) shows the situation where exchange rate shocks are the dependent variable. Considering the estimation results, it is concluded that the established models are dynamic, but the long-term coefficients are not statistically significant.

\begin{tabular}{lc}
\hline Test & Statistics \\
\hline$\widetilde{\Delta}$ & $4.086^{* * * *}$ \\
\hline$\Delta$ adj & $4.320^{\text {**** }}$
\end{tabular}

Note: ***Indicates statistical significance at the $1 \%$ level

Demand and exchange rate

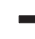


AEA

29,86

\section{4}

Finally, the Dumitrescu and Hurlin's (2012) Granger non-causality test is applied to determine the causality relationship between the two series, and the results are presented in Table 9. Accordingly, it is found that there is a causal relationship running from the exchange rate shocks to the demand shocks. In other words, in the tourism sector, the demand shocks are caused by the exchange rate shocks, whereas the exchange rate shocks are not caused by the demand shocks.

\section{Concluding remarks}

Tourism revenues are important for the budget, and they also help to narrow the foreign trade deficits. Therefore, the volatilities in tourism demand are crucial for the policymakers. The volatilities in the exchange rates, on the other hand, play an important role in determining the export and import structures of the countries, and they also contribute to the determination of the supply and demand structure of the tourism sector.

Although the tourism demand depends on the circumstances such as the region's unique natural beauties and climate, it also varies depending on the prices in the region and the international price differences. As it is known from the economic theory, to create an equilibrium in the market, the quantity of supply and demand must be balanced at a specific price. In a highly competitive sector, if the prices are high, the tourism demand will be shifted to the country where the service could be obtained at a lower price. While the low price is an attractive factor, too low service quality could lead to a decline in the demand for tourism in the following periods. For this reason, the facilities that compromise the quality of service with a low-price policy will struggle in the long run.

For the tourism sector, this study prefers a socioeconomic approach rather than a sociocultural approach and aims to clarify how the changes and/or uncertainties experienced directly in exchange rates interact with the tourism demand. Empirical findings show that the Westerlund-Durbin-Hausman test, which is used to determine the long-term relationship between tourism demand shocks and exchange rate shocks, shows that there is a cointegration relationship, but no significant result has been obtained in long-term coefficients. Consequently, it is not possible to comment on the direction of the relationship between tourism demand shocks and exchange rate shocks, based on the empirical findings. At this point, it can be said that the theoretical strategy of low price-high competition, which is widely agreed for the goods market, is not true in the long term for the tourism sector.

\begin{tabular}{lccc}
\hline & & Lag order= & \\
Null hypothesis & $W_{N, T}^{H n c}$ & $Z_{N, T}^{\text {Hnc }}$ & $Z_{N}^{\text {Hnc }}$ \\
\hline$d r_{e} x c \rightarrow d r_{i} t r$ & 4.0061 & $10.8387 * * *$ & $8.5064^{* * * *}$ \\
$d r_{i} t r \rightarrow d r_{e} x c$ & 1.3688 & 1.3296 & 0.7395 \\
& $W_{N, T}^{H n c}$ & Lag order= & $Z_{N, T}^{H n c}$ \\
$d r_{e} x c \rightarrow d r_{i} t r$ & 4.2196 & $5.6589^{* * *}$ & $Z_{N}^{H n c}$ \\
$d r_{i} t r \rightarrow d r_{e} x c$ & 1.8385 & -0.4116 & $3.7362^{* * * *}$ \\
& & Lag order= & -0.8639 \\
& $W_{N, T}^{H n c}$ & $Z_{N, T}^{H n c}$ & $Z_{N}^{H n c}$ \\
$r_{e} x c \rightarrow d r_{i} t r$ & 3.9867 & $2.0540^{* * *}$ & 0.6231 \\
$d r_{i} t r \rightarrow d r_{e} x c$ & 3.2183 & 0.4545 & -0.4620 \\
Note: $* * *$ and $* *$ indicate statistical significance at the 1 and $5 \%$ level, respectively & \\
\hline
\end{tabular}

Table 9.

Dumitrescu and Hurlin (2012) Granger noncausality test results 
This study also analyzes whether the effects of the exchange rate and demand shocks are temporary or permanent for the tourism sector of the selected countries. Accordingly, as a result of the panel unit root analyzes for both series, it is concluded that the effects of both the exchange rate and demand shocks are temporary in these countries. At this point, this study is a pioneering study in the tourism sector in terms of defining the exchange rate and demand shocks and analyzing their effects.

Finally, it has been recognized that the latest COVID-19 pandemic has had a dramatic effect on the global economy, with global demand and supply shocks predicted worldwide. In particular, the supply and demand sides of the tourism industry have been influenced by this pandemic. Therefore, the results of this study could give an insight into the practitioners about the probable exchange rate and the demand shocks in the tourism sector in the forthcoming days. Moreover, in further studies, forecasts could be made for the length of the shocks triggered by this pandemic in the tourism industry, which may also contribute to the literature.

\section{References}

Balli, F., Shahzad, S.J.H. and Salah Uddin, G. (2018), "A tale of two shocks: what do we learn from the impacts of economic policy uncertainties on tourism?", Tourism Management, Vol. 68, pp. 470-475, doi: 10.1016/j.tourman.2018.04.008.

Bhattacharya, M. and Narayan, P.K. (2005), "Testing for the random walk hypothesis in the case of visitor arrivals: evidence from Indian tourism", Applied Economics, Vol. 37 No. 13, pp. 1485-1490.

Bozkurt, K. and Bahar, O. (2015), "Talep şokları: Turizm sektörü için bir analiz”, Anatolia: Turizm Araştırmalan Dergisi, Vol. 26 No. 1, pp. 29-41.

Breusch, T.S. and Pagan, A.R. (1980), "The lagrange multiplier test and its applications to model specification tests in econometrics", The Review of Economic Studies, Vol. 47 No. 1, pp. 239-253.

Central Bank of Republic of Turkey (2020), available at: https://evds2.tcmb.gov.tr/ (accessed 27 May 2020).

Chudik, A. and Pesaran, M.H. (2015), "Common correlated effects estimation of heterogeneous dynamic panel data models with weakly exogenous regressors", Journal of Econometrics, Vol. 188 No. 2, pp. 393-420.

Dritsakis, N. (2004), "Cointegration analysis of German and British tourism demand for Greece", Tourism Management, Vol. 25 No. 1, pp. 111-119.

Dumitrescu, E.-I. and Hurlin, C. (2012), "Testing for granger non-causality in heterogeneous panels", Economic Modelling, Vol. 29 No. 4, pp. 1450-1460.

Eliat, Y. and Einav, L. (2004), "Determinants of international tourism: a three dimensional panel data analysis”, Applied Economics, Vol. 36, pp. 1315-1327.

Lean, H.H. and Smyth, R. (2009), "Asian financial crisis, avian flu, and terrorist threats: are shocks to Malaysian tourist arrivals permanent or transitory?", Asia Pacific Journal of Tourism Research, Vol. 14 No. 3, pp. 301-321.

Lee, C.G. (2009), "Are tourist arrivals stationary? Evidence from Singapore”, International Journal of Tourism Research, Vol. 11 No. 4, pp. 409-414.

Lumsdaine, R. and Papell, D. (1997), "Multiple trend breaks and the unit root hypothesis", Review of Economics and Statistics, Vol. 79 No. 2, pp. 212-218.

Maddala, G.S. and Wu, S. (1999), "A comparative study of unit root tests with panel data and a new simple test", Oxford Bulletin of Economics and Statistics, Vol. 61 No. S1, pp. 631-652.

Narayan, P.K. (2005), "The structure of tourist expenditure in Fiji: evidence from unit root structural break tests", Applied Economics, Vol. 37 No. 10, pp. 1157-1161. 
Patsouratis, V., Frangouli, Z. and Anastasopoulos, G. (2005), "Competition in tourism among the Mediterranean countries”, Applied Economics, Vol. 37 No. 16, pp. 1865-1870.

Pesaran, M.H. (2004), "General diagnostic tests for cross section dependence in panels", Cambridge Working Papers in Economics 0435, Department of Applied Economics, University of Cambridge.

Pesaran, M.H. (2006), "Estimation and inference in large heterogeneous panels with multifactor error structure", Econometrica, Vol. 74 No. 4, pp. 967-1012.

Pesaran, M.H. and Yamagata, T. (2008), "Testing slope homogeneity in large panels", Journal of Econometrics, Vol. 142 No. 1, pp. 50-93.

Santana-Gallego, M., Ledesma-Rodriguez, F.J. and Perez-Rodriguez, J.V. (2010), "Exchange rate regimes and tourism”, Tourism Economics, Vol. 16 No. 1, pp. 25-43.

Shareeff, R. and McAleer, M. (2005), "Modelling international tourism demand and volatility in small island tourism economies", International Journal of Tourism Research, Vol. 7 No. 6, pp. 313-333.

Smyth, R., Nielsen, I. and Mishra, V. (2009), 'I've been to Bali too' (and I will be going back): are terrorist shocks to Bali's tourist arrivals permanent or transitory?", Applied Economics, Vol. 41 No. 11, pp. 1367-1378.

The World Bank DataBank (2020), available at: https://databank.worldbank.org/source/worlddevelopment-indicators (accessed 27 May 2020).

Toh, R.S., Khan, H. and Ng, F.T. (1997), "Prospects for the tourism and hotel industry in Singapore: a regression model", Cornell Hotel and Restaurant Administration Quarterly, Vol. 38 No. 5, pp. 80-87.

Webber, A.G. (2001), "Exchange rate volatility and cointegration in tourism demand", Journal of Travel Research, Vol. 39 No. 4, pp. 398-405.

Westerlund, J. (2008), "Panel cointegration tests of the fisher effect", Journal of Applied Econometrics, Vol. 23 No. 2, pp. 193-223.

Zivot, E. and Andrews, D. (2002), "Further evidence of the great crash, the oil-price shock and the unitroot hypothesis", Journal of Business and Economic Statistics, Vol. 20 No. 1, pp. 25-44. 


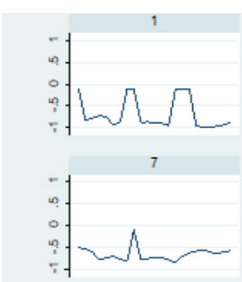

13

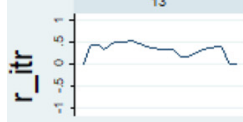

19

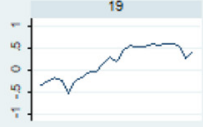

25

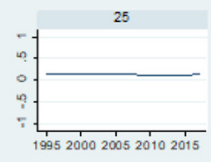

Graphs by id

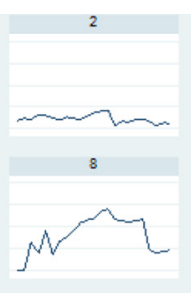

14

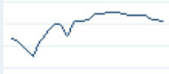

20

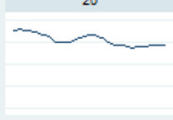

28

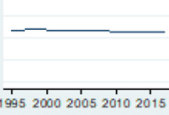

$T_{19952000200520102015}^{\prime}$

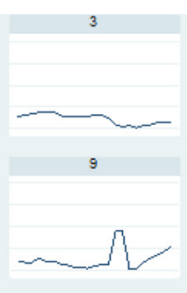

15

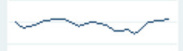

21

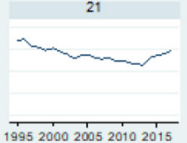

$\longdiv { 1 9 9 5 2 0 0 0 2 0 0 5 2 0 1 0 2 0 1 5 }$

$1 9 \longdiv { 9 5 2 0 0 0 2 0 0 5 2 0 1 0 2 0 1 5 }$
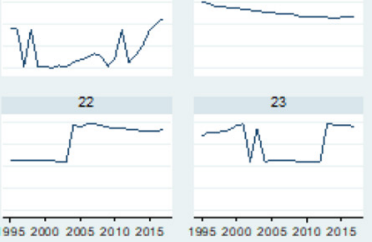

$\longdiv { 1 9 9 5 2 0 0 0 2 0 0 5 2 0 1 0 2 0 1 5 }$

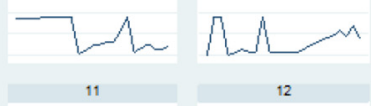

Figure A1.

Descriptive statistics graphics of tourism demand shock 


\section{AEA \\ 29,86}

188

Figure A2.

Descriptive statistics graphs of exchange rate shock

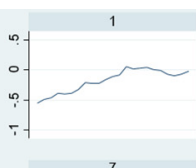

7

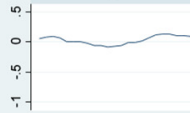

13

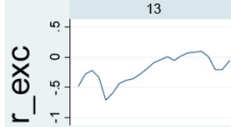

19
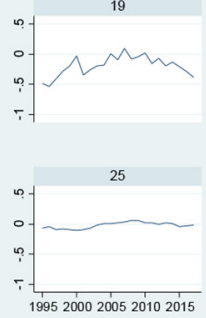

Graphs by id

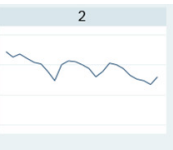

8

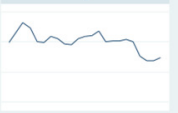

14

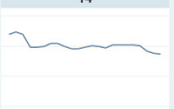

20

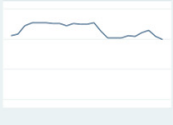

26

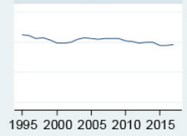

19952000200520102015

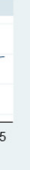

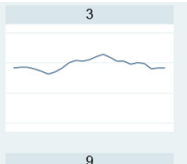

9

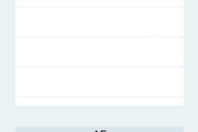

15

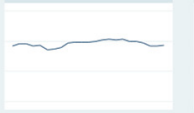

21

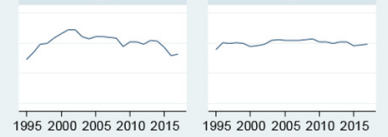

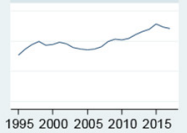

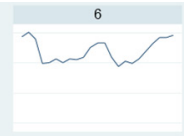

12

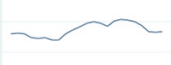

17
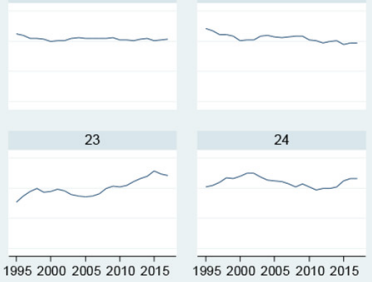

$1 9 9 5 2 0 0 0 2 0 0 5 2 0 1 0 2 0 1 5 \quad \longdiv { 1 9 9 5 2 0 0 0 2 0 0 5 2 0 1 0 2 0 1 5 } \stackrel { 1 9 9 5 2 0 0 0 2 0 0 5 2 0 1 0 2 0 1 5 } { 1 9 9 5 2 0 0 0 2 0 0 5 2 0 1 0 2 0 1 5 }$ year

\section{Corresponding author}

Zeliha Can Ergün can be contacted at: zeliha.can@adu.edu.tr

For instructions on how to order reprints of this article, please visit our website: www.emeraldgrouppublishing.com/licensing/reprints.htm

Or contact us for further details: permissions@emeraldinsight.com 